\title{
Learning to Become Instructional Coaches in Health and Physical Education
}

\author{
Tim Fletcher and Ken Lodewyk \\ Brock University \\ Katie Glover and Sandra Albione \\ Ophea
}

\begin{abstract}
Purpose: To examine the experiences of a cohort of health and physical education teachers and consultants who were learning to become instructional coaches. Methods: Three surveys and three focus groups were administered to 14 participants over 9 months to consider their experiences of learning to become instructional coaches. Concepts from expectancyvalue theory guided analyses of both quantitative and qualitative data. Results: Participants reported positive experiences learning to become instructional coaches. Understanding and importance-utility value increased significantly between the administration of initial and end surveys. Focus group data generally supported quantitative findings while enabling more specific insights to be gained, particularly regarding specific moments of participants' learning that led to a shift in thinking or practice. Conclusions: Participants valued their experiences learning to become instructional coaches and identified the instructional coaching model as a powerful form of job-embedded professional learning based on teachers' context-specific needs.
\end{abstract}

Keywords: curriculum renewal, facilitators, pedagogy, professional development, professional learning

In February 2015, the Ontario Ministry of Education (2015a, $2015 b$ ) released a fully revised health and physical education (H\&PE) curriculum for elementary and secondary schools, with implementation in classrooms to begin in September 2015. During times of curriculum change in H\&PE, it is crucial that the teachers responsible for implementing that change are supported in their implementation efforts. Despite the best intentions and concerted actions of curriculum developers and administrators, unless teachers are provided with strong support based on their needs at the time of implementation, change efforts are seemingly doomed for failure or at the very least, disappointment (Baird \& Clark, 2018; Goodyear \& Casey, 2015). Moments of curriculum change therefore offer critical periods to support teachers through targeted efforts to sustain their ongoing professional learning and development.

In April and May 2015, the Ministry of Education and Ophea (a nonprofit organization that supports H\&PE programs in Ontario) ran implementation training sessions for expanded school board teams, representatives from public health units, and other stakeholder groups. The sessions enabled some valuable baseline data to be gathered regarding the perceived capacity of teachers to implement the revised $\mathrm{H} \& \mathrm{PE}$ curriculum following its introduction. Yet, several labor disruptions, the increased depth and scope of curriculum content, and varied levels of individual school board capacity had an impact on implementation across Ontario. These factors warranted a more concerted and systematic effort to support teachers in using the revised curriculum. In collaboration with curriculum consultants from H\&PE and other subject areas, Ophea and the Ministry of Education identified instructional coaching as a

Fletcher and Lodewyk are with the Department of Kinesiology, Brock University, St. Catharines, Ontario, Canada. Glover and Albione are with Ophea, Toronto, Ontario, Canada. Address author correspondence to Tim Fletcher at tfletcher@brocku.ca. promising form of professional learning to support teachers in implementing the revised curriculum. The purpose of this study was to examine the experiences of a cohort of H\&PE teachers and consultants learning to become instructional coaches who would, in turn, facilitate the professional learning of teachers tasked with implementing the revised curriculum.

\section{Instructional Coaching as a Form of Professional Learning}

The dominant model of professional learning and development in $\mathrm{H} \& \mathrm{PE}$ has been identified as weak in its effectiveness and ability to invoke sustainable change in teachers' practices (Armour \& Yelling, 2004). In the dominant model, an external "expert" is typically brought to a school or school board for a brief period (often no more than 1 day), where the topic of interest is introduced in a decontextualized environment such as a conference room, and teachers are then left to take or leave the idea and its implementation. It is, therefore, of little surprise that such approaches can lead to fragmentation and incoherence in terms of teachers' learning (Darling-Hammond \& McLaughlin, 2011) and offer little that helps teachers improve student learning (Sparks, 2002). New approaches that offer sustained, personalized, and highly contextualized support now constitute the desired platform for professional learning. Furthermore, Armour, Quennerstedt, Chambers, and Makopoulou (2017) recommend that "effective" professional learning and development must:

(i) focus on the dazzling complexity of the learning process; (ii) prioritise context and contemporary challenges; (iii) bridge research/theory-practice in innovative ways; and (iv) nurture the career-long growth of PE teachers. (p. 799) 
In addition to these overarching characteristics and in line with recent claims about effective professional development made by Darling-Hammond, Hyler, and Gardner (2017), a major review of literature led Parker and Patton (2016) to identify the following features of "effective" professional learning and development for contemporary H\&PE practice:

a. It is collaborative and job-embedded, meaning that it is situated to the greatest extent possible in the contexts in which educational practice occurs (i.e., in classrooms and gymnasia).

b. Participants have some ownership and investment in the process. This typically involves teachers identifying their specific needs based on the unique contexts in which they work.

c. Participants are provided with tools and situations where they can engage in sustained interaction with colleagues and professional learning facilitators.

d. Teachers' knowledge and skills related to pedagogy and content are enhanced, with a distinct focus on using the improved knowledge and skills to improve student learning.

Parker, Patton, and O'Sullivan (2016) identify critical dialogue, public sharing of work, and communities of learners as signature pedagogies of professional learning in physical education.

Patton, Parker, and Neutzling (2012), and Patton and Parker (2014) suggest that facilitators of professional learning (a role we suggest is played by instructional coaches) take on a critical but largely unexplored role in times of reform. Patton et al. (2012) emphasize the important role played in the selection of facilitators of professional learning, particularly in terms of the beliefs about teacher learning held by the facilitators. Patton et al. (2012) found that facilitators of professional learning in physical education tended to take a constructivist approach to teacher learning, believing that meaning is constructed in a social environment based on prior knowledge and experiences situated in the contexts of one's own teaching practice. Of particular importance was a view held by facilitators that professional learning is best conceptualized as teacher-centered and focused on the needs of teachers as they relate to the particular circumstances they face in their own contexts.

With these general principles of professional learning in mind, instructional coaching is one approach that provides many of these features, having been identified as a powerful means to improve teachers' knowledge, skills, and practice (Desimone \& Pak, 2017). Such has been the uptake of instructional coaching in the United States, that instructional coaches have been identified as playing a crucial role in a broader, more coherent system of supports during times of reform (Woulfin \& Rigby, 2017). Although instructional coaching has seen relatively widespread uptake in many subject areas including literacy (Lynch \& Ferguson, 2010) and mathematics (Bruce \& Ross, 2008), particularly in North America, we were unable to identify any empirical reports of its use in H\&PE. Given this gap, there is a sense of urgency to learn from successful approaches in other subfields of education and apply them to H\&PE.

According to Knight (2009), instructional coaching provides focused and differentiated support to teachers to assist them in implementing strong teaching practices. Instructional coaches work in partnership with teachers (often in small groups) and "frequently model practices in the classroom, observe teachers, and engage in supportive, dialogical conversations with them about what they observed" (p. 30). Knight identifies the following features of the instructional coaching model: a. Equality: Instructional coaches and teachers are partners in the coaching relationship. Therefore, instructional coaches must have some currency and credibility with educators in order to relate to their specific needs and contextual situations.

b. Choice: Teachers are able to choose what they wish to learn about and how (e.g., on-site, online, frequency, etc.), using a collaborative, inquiry-based learning approach rather than have their learning dictated to them from their superiors.

c. Voice: Instructional coaching should provide teachers with opportunities to express themselves, empowering and respecting their professional opinions about their learning.

d. Dialog: Instructional coaching should enable meaningful and authentic dialog to be established and engaged in between coaches and teachers.

e. Reflection: Teachers are provided with time and space to help make sense of their learning.

f. Praxis: Teachers are able to enact what they have learned in practice, and reflect on/assess the extent to which their learning has made positive impacts on practice and student learning.

g. Reciprocity: Instructional coaches should benefit from the coaching relationship, learning about practice from their sustained engagement with teachers and educational practice.

Although the principles of instructional coaching have been fairly well established and preliminary evidence is pointing toward its effectiveness as a powerful form of professional learning (Mangin \& Dunsmore, 2015), there is little research to explain how one learns to become an instructional coach, particularly in H\&PE. As such, our focus in this inquiry is on participants' experiences of learning to become instructional coaches. We intend to consider the experiences of teachers who learn from/with instructional coaches in subsequent studies. Gallucci, Van Lare, Yoon, and Boatright (2010) identified the need to consider the learning experiences of instructional coaches themselves, due to the tendency for school districts to view coaches as "unproblematic conduits of reform ideas" (p. 919). These authors identified the importance of attending to the learning needs of new instructional coaches, who were themselves often coming to terms with new content and pedagogies during times of reform. Gallucci et al. (2010) further suggest that the process of becoming an instructional coach does not occur quickly, with coaches needing time to come to terms with their role and the approaches being espoused by the authorities who govern the conditions of reform.

\section{Expectancy-Value Theory}

In order to examine the experiences of participants who were learning to become instructional coaches in H\&PE, we framed the study using expectancy-value theory (Wigfield \& Eccles, 2000). Expectancy-value theory suggests that engagement with a task and subsequent achievement partially, yet prominently, hinges on one's task values (the rationale for engaging in a task or pursing a goal) and their expectancy beliefs (perceptions of competence and expectations of a particular outcome) relative to the particular task or goal. For example, in achievement settings, participants' motivation for a task depends on their perceptions of competence and expectations for successfully completing the task, along with the perceived interest, importance, usefulness, and cost (e.g., effort or time) associated with engaging in the task. Empirical support for 
expectancy-value theory signals that such expectancies and task values are linked to achievement, particularly through their influence on related processes such as cognitive processing, choice, and persistence on learning tasks (Wigfield \& Eccles, 2000). Expectancies and values have also been linked to teachers' engagement and persistence in professional learning programs. For example, Thomson and Kaufmann (2013) found that such outcomes were significantly more likely in science teachers who had higher levels of self-efficacy for teaching and content knowledge in science. Foley (2011) reported that both expectancy and value predicted K-3 teachers' implementation of a Comprehensive Strategy Instruction program, and that school support facilitated that implementation. Finally, in a qualitative study of science teachers paired for 6 weeks with a mentor scientist, Grove, Dixon, and Pop (2009) noted increases in the tone and accuracy of teachers' statements about inquiry-based learning and some positive pedagogical adaptations.

With this theoretical background in mind, the questions guiding the research were as follows: (a) What are participants' experiences of learning to be instructional coaches and to use the instructional coaching model in H\&PE? and (b) To what extent was Ophea able to provide participants with experiences that built participants' knowledge and confidence to be instructional coaches?

\section{Methods}

Participants in this research were 14 instructional coaches from eight school boards in Ontario, Canada. As shown in Table 1, eight worked full-time as curriculum consultants, with six of those specializing in H\&PE (the remaining two were responsible for several subject areas). One participant's workload was half-time H\&PE consultant and half-time H\&PE teacher. Five participants were regular teachers in schools (three were H\&PE specialists) who took on the role of instructional coach in addition to their regular duties. At the outset of the project, several potential participating school boards were identified based on criteria such as level of

\section{Table 1 Participants' Roles in Their School Boards}

\begin{tabular}{lll}
\hline $\begin{array}{l}\text { Participant } \\
\text { No. }\end{array}$ & $\begin{array}{l}\text { H\&PE } \\
\text { Specialist? }\end{array}$ & $\begin{array}{l}\text { Regular Role in } \\
\text { School Board }\end{array}$ \\
\hline 1 & Y & H\&PE teacher (Sec.) \\
2 & Y & H\&PE teacher (Sec.) \\
3 & Consultant for several subjects (Elem.) & Teacher for several subjects (Elem.) \\
4 & N & H\&PE consultant (Elem./Sec.) \\
5 & Y & H\&PE consultant (Sec.) \\
6 & Y & Teacher for several subjects (Elem.) \\
7 & N & H\&PE consultant (Elem.) \\
8 & Y & H\&PE consultant (Elem.) \\
9 & Y & Consultant for several subjects (Elem.) \\
10 & N & H\&PE consultant (Elem./Sec.) \\
11 & Y & H\&PE teacher/H\&PE consultant (Elem.) \\
12 & Y & H\&PE consultant (Elem./Sec.) \\
13 & Y & H\&PE teacher (Sec.) \\
14 & Y &
\end{tabular}

Note . Elem. = elementary division; Sec. $=$ secondary division; $\mathrm{H} \& \mathrm{PE}=$ health and physical education. implementation of the revised H\&PE curriculum (i.e., a range from minimal to full implementation and administrative support), representation across demographics (e.g., urban/suburban/rural), and representation of teachers within boards who had shown an interest in instructional coaching.

\section{The "Intervention": Key Features in Learning to Become Instructional Coaches}

In its role as an association supporting the professional learning needs of educators in Ontario, Ophea provided the following supports and opportunities (listed in order of implementation) to support participants' learning about instructional coaching:

a. In August 2016, Ophea hosted a 1-day orientation session for all instructional coaches, which included: introduction and familiarization sessions run by Ophea staff and instructional coaching leaders from other subject areas, activities where coaches were introduced to each other, and invitations to participate in an H\&PE instructional coaches' network that involved face-to-face and online activities.

b. Coaches were encouraged to identify teachers in their respective boards whose needs could be supported through instructional coaching. Ophea provided tools for coaches to develop an action plan based on the needs of the identified teachers in their boards.

c. Ophea provided funds to the participating school boards to cover release time and travel expenses incurred by instructional coaches (e.g., time and travel to work with teachers in their board). It should be noted that even with these funds, not all coaches were able to attend all activities in the intervention. This was often due to significant travel time or other commitments in participants' school boards.

d. Ophea provided tools and support for coaches to participate in an online learning community, offering opportunities for discussion and collaboration. Electronic curriculum resources (such as planning documents and introductory learning modules for new content strands and pedagogical models) were made available through this software.

e. Coaches were invited to participate in two telewebinars, where they could learn more about instructional coaching, as well as share ideas.

f. Coaches were provided with ongoing access to two H\&PE curriculum consultants who attended in-person sessions and telewebinars and also provided individualized consultation for each of the coaches.

g. Ophea hosted a half-day session at its annual conference in October 2016, where coaches could learn more strategies and ideas regarding instructional coaching.

h. Ophea hosted a final full-day session in February 2017, where coaches identified key moments of their learning and perceived outcomes for teachers with whom they worked.

\section{Data Sources}

A mixed-method approach was used to gather and analyze quantitative and qualitative data to provide broad and deep understandings of the perspectives of the participants learning to be instructional coaches. The design consisted of three phases: (a) initial test (August 2016), (b) mid test (September-December 
2016), and (c) posttest (April 2017). In each of the three phases, survey and focus group data were generated that addressed coaches' understanding, self-efficacy, and importance-utility value (IUV) to both implement the revised H\&PE curriculum and to use instructional coaching to support teachers' needs in their boards. Several Likert and open-ended survey items and focus group questions were designed to collect information about the value participants placed on instructional coaching in terms of its importance and usefulness/utility as a form of professional learning.

Quantitative data about participants' engagement with instructional coaching were gathered through periodic administrations of a short Likert-style survey, which was developed for the purposes of this study. The initial-, mid-, and posttest survey data were used for this study. The survey consisted of 17 items representing three scales: knowledge (six items), self-efficacy (two items), and IUV (nine items). A 5-point Likert scale (1= strongly disagree, $5=$ strongly agree) was used for each item. From the stem, "I presently believe I have a high level of understanding ... ," the knowledge scale items assessed instructional coaches' self-reported understanding of instructional coaching and how it works; the revised H\&PE curriculum, their board's needs, and how instructional coaching enabled them and their board to effectively implement the revised H\&PE curriculum. Examples of items assessing understanding are: "I presently believe I have a high level of understanding of the instructional coaching model and how it works," and "I presently believe I have a high level of understanding of my board's needs regarding effective implementation of the revised H\&PE curriculum." In line with items previously validated (Pintrich, Smith, Garcia, \& McKeachie, 1991), the stem "I presently feel confident that I can ... " represented self-efficacy scale items, which assessed instructional coaches' confidence that they could effectively teach and help other teachers to implement the newly revised H\&PE curriculum. An example of an item assessing self-efficacy is, "I presently feel confident that I can successfully help other educators to effectively implement the revised H\&PE curriculum." IUV represented the degree that participants generally valued instructional coaching as important for fulfilling their professional role and for equipping teachers in their board. It also assessed the perceived usefulness of instructional coaching for helping teachers to successfully implement the 2015 H\&PE curriculum through its facilitation of meeting their needs and by improving their abilities, professional growth, collaborations, and use of an action plan. Two question stems from a validated task value measure (Pintrich et al., 1991) were used to begin each of the items assessing IUV. The stem for items assessing importance was "I presently value what the Instructional Coaching Model can provide ..." (e.g., "I presently value what the Instructional Coaching Model can provide me in my professional role"); while utility (usefulness) items began with "From what I understand of the Instructional Coaching Model, I believe it can improve ..." (e.g., "From what I understand of the Instructional Coaching Model, I believe it can improve how educators' needs are met in H\&PE").

Initial test. At the initial orientation session, 12 of the 14 total participants were in attendance. In the session, participants were introduced to the principles and concepts of instructional coaching, and to proposed learning tasks throughout the duration of the project. Following this session, participants completed the first survey and a focus group interview. The latter was conducted with two groups of six participants to gain deeper understanding of their self-efficacy to implement the revised H\&PE curriculum and instructional coaching. Focus group interviews were semistructured, with several guiding overarching questions. Example questions included, "What are some of the main concerns you have in supporting educators in your board to effectively implement the 2015 H\&PE curriculum?" and "How might the instructional coaching model help you address some of these concerns?" The interviewers probed participant responses to gain deeper insight, clarify responses, and ensure understanding. Participants were encouraged to build on, agree/disagree with, or respond to other participants' responses.

Midtest. The midtest phase consisted of one focus group interview conducted with 13 of the 14 total participants (one group of six and one group of seven participants) in October of 2016, and one survey administered in December of 2016. In addition to seeking deeper understanding of coaches' self-efficacy to implement the revised H\&PE curriculum and to become instructional coaches, focus group items generated examples of successes and challenges, as well as enabling the identification of suggestions for improvement in facilitating their learning about becoming instructional coaches. Example questions included: (a) "In comparison to previous forms of professional development you have experienced, how effective are you finding the instructional coaching model?" (b) "What are you seeing as its main benefits?" and (c) "What are you seeing as its main drawbacks?" The midtest survey contained the same 17 Likert-style items as were asked in the initial-test phase and was administered electronically.

Posttest. Ophea conducted a final orientation session at which nine of the 14 participants were present, to consolidate their learning and identify avenues for further exploration related to instructional coaching. Following this, participants completed a final (posttest) focus group interview and survey. Two focus groups interviews were conducted, one with four participants and one with five participants, to gain deeper understanding of coaches' experiences of success, the features of their learning that were helpful and those that were not, and their recommendations for future opportunities of learning to become instructional coaches. An example question posed during the final focus group interview was, "What is something the instructional coaching model has enabled you to be successful with in supporting educators in your board to effectively implement the 2015 H\&PE Curriculum?" The final survey was completed electronically and consisted of the same 17 items assessed in the initial- and midtest surveys. In addition, there were two Likert-style questions and seven open-ended questions that were included to gather participants' summative views on their experiences of learning to become instructional coaches. The additional two Likert items asked participants to score the extent to which their experience with instructional coaching was positive, and the extent to which they perceived the teachers they worked with from their board had a positive experience. The seven openended items enquired about the ways in which instructional coaching helped the coaches equip teachers to better implement the H\&PE curriculum, the features and activities provided by Ophea that should be kept or modified, the levels of support they received in enacting instructional coaching and the levels they think are desirable, and whether or not they would participate in a similar initiative again or recommend that others participate.

\section{Analysis}

The 17 Likert-style items from each administration (i.e., initial, mid, and post) of the survey were entered into the Statistical 
Package for the Social Sciences (version 22; IBM, Armonk, NY) and screened for normality (e.g., skew and kurtosis). Descriptive statistics and Pearson bivariate correlations were computed for understanding, self-efficacy, and IUV relative to each administration of the survey. One-way repeated-measures analysis of variance $(p<.05)$ was conducted to compare the variations in levels of understanding, self-efficacy, and IUV over the three assessment points during the intervention. A power analysis for this statistical procedure $(p<.05)$ revealed a minimum sample size of 8 equating with the shared sample size across the three repeated measures for this analysis. Although this analysis and guidelines by Tabachnick and Fidell (2006) indicate that this sample size was adequate, effect sizes were also reported, and findings are interpreted with some caution because of the small sample size.

Qualitative data generated from open-ended survey items and focus group interviews were transcribed verbatim. Participants were given a pseudonym to protect their identities and those of the boards they represented. Member-checking involved sending transcripts to participants, where they were asked the extent to which their responses and the meaning of their responses accurately reflected their thoughts and experiences. Participants were offered the opportunity to edit their responses so that accuracy was ensured. Analysis of focus group interviews was at first inductive, where codes were generated from the transcripts. These codes were compiled thematically to identify (a) value placed on instructional coaching, (b) coaches' self-efficacy to implement the revised H\&PE curriculum and instructional coaching, and (c) identification of strategies and approaches for future application.

Quantitative and qualitative data were compared with identifying common themes, patterns, and concerns across all data sources, as well as any disconfirming cases. Moreover, qualitative data sources were searched for instances where they could help provide further depth to the quantitative analyses. For example, qualitative data sources help provide a clearer picture for the reasons why scores changed regarding the extent to which Ophea's approach to instructional coaching provided opportunities for collaboration among coaches. These triangulation techniques help add to the rigor and trustworthiness of the data analysis.

\section{Results}

Scale descriptive statistics and alpha reliability coefficients for each of the three (initial, mid, and post) assessment points are provided in Table 2. The alpha reliability coefficients were all satisfactory (>.68) particularly for scales with less than 10 items (Loewenthal, 1996), which meant that mean (scale) scores for the items could be used. The correlations between each scale for each assessment time are provided in Table 3. These signal that, except for the relationship between self-efficacy and IUV initially in the study, relationships between understanding, self-efficacy, and IUV at each assessment point were positive, significant $(p<.05)$, and moderate-to-high (.40-.86).

Statistical differences in understanding, self-efficacy, and IUV across the three assessment points tested by repeated-measures analysis of variance revealed significant differences between time points in understanding, $F(2,12)=4.61, p=.033$, ES $=0.44$; selfefficacy, $F(2,12)=6.09, p=.015$, ES $=0.50$; and IUV, $F(2,12)=$ $10.87, p=.002, \mathrm{ES}=0.64$. In considering which of these constructs changed significantly by assessment time, post hoc tests revealed that participants' self-efficacy $(p=.012)$ and IUV $(p=.04)$ increased significantly between initial and mid points; none of
Table 2 Scale Alpha Reliability and Descriptive Statistics by Assessment Point

\begin{tabular}{lccc}
\hline Scale & Initial $(\boldsymbol{n}=\mathbf{8})$ & Mid $(\boldsymbol{n}=\mathbf{1 2})$ & Post $(\boldsymbol{n}=\mathbf{1 4})$ \\
\hline Understanding & & & \\
$M(S D)$ & $4.06(0.45)$ & $4.28(0.60)$ & $4.22(0.55)$ \\
$\alpha$ & .74 & .88 & .80 \\
Self-efficacy & & & \\
$M(S D)$ & $4.19(0.46)$ & $4.54(0.54)^{*}$ & $4.42(0.57)$ \\
$\alpha$ & .68 & .83 & .73 \\
Importance-utility value & & \\
$M(S D)$ & $4.08(0.34)$ & $4.40(0.66)^{*}$ & $4.56(0.40)^{* *}$ \\
$\alpha$ & .76 & .96 & .86 \\
\hline
\end{tabular}

Note. $\alpha=$ alpha reliability coefficient.

*Statistical difference between the initial and midway assessment points. **Statistical difference between the initial and post assessment points.

\section{Table 3 Scale Pearson Correlations by Assessment Point}

\begin{tabular}{lccccccc}
\hline \multirow{2}{*}{ Factor } & \multicolumn{3}{c}{ Understanding } & & \multicolumn{3}{c}{ Self-Efficacy } \\
\cline { 2 - 4 } \cline { 7 - 8 } & Initial & Mid & Post & & Initial & Mid & Post \\
\hline Self-efficacy & $.75^{*}$ & $.71^{*}$ & $.85^{*}$ & & - & - & - \\
$\begin{array}{l}\text { Importance-utility } \\
\text { value }\end{array}$ & .40 & $.71^{*}$ & $.86^{*}$ & & .14 & $.70^{*}$ & $.58^{*}$ \\
\hline
\end{tabular}

Note. ${ }^{*} p<.05$.

the scales changed significantly between the mid and post points; and understanding $(p=.052)$ and IUV $(p=.004)$ increased significantly between the initial and post points. Assumptions of sphericity and normality were met for each construct (Tabachnick \& Fidell, 2006). It is worth focusing in more depth on the ways in which changes were noted according to the tenets of expectancyvalue theory. In the following sections we demonstrate ways in which the quantitative and qualitative data corroborated or disconfirmed each other according to participants' understanding, self-efficacy, and IUV of instructional coaching.

\section{Understanding}

Participants demonstrated increases in their understanding of instructional coaching and of the 2015 H\&PE curriculum and its implementation through the duration of the project. As reported earlier, statistically significant increases were noted initial- to posttest. These positive changes were supported by analysis of focus group and open-ended survey data. Several comments from the focus group suggest that the change in understanding of the H\&PE curriculum came specifically from participants' engagement with instructional coaching. Analysis of focus group data showed that increases in understanding applied mostly to those instructional coaches whose roles extend beyond the H\&PE content area. Several participants made note of this, with Participant 4 providing a particularly rich description of how this occurred as a result of learning to become an instructional coach:

I think this project allowed me to deepen my own understanding of the [H\&PE] curriculum as well. In my role, I have got three different curriculums I am in charge of and this project 
really made me focus more on the H\&PE curriculum. So not only the added resources of co-planning, co-teaching and seeing each other and maybe changing some of our teaching practices and taking our practices further, but also deepening my own learning ... I think the resources, the understanding of the curriculum, building our own pedagogy, but I also think that the taking the risks together, that was a big part of it. Working together, being able to go into someone's class and actually try out something.

A point that stands out from Participant 4's comment and those made by several other focus group participants is the way that working collaboratively with the teachers provided an impetus for the growth she experienced during the project. Importantly, Participant 4 went on to explain that deeper understanding of the H\&PE curriculum not only improved her own professional learning, it enabled her to take on a more active advocacy role for H\&PE in her school board, a role now grounded in knowledge of the revised H\&PE curriculum. "I think there needs to be a stronger advocate for that in my particular board and I think [without] this project I wouldn't have been doing that as much as I can." The increase in understanding of the curriculum therefore enabled Participant 4 to act as a change agent both inside and outside of the classrooms of teachers with whom she collaborated.

\section{Self-Efficacy}

Focus group data supported findings that learning to become instructional coaches influenced participants' confidence to implement the 2015 H\&PE curriculum or to help other educators implement the curriculum. All but one of the nine participants in the final focus group spoke of how their confidence was influenced during the project. For some, changes in confidence were general in nature (e.g., "I am pretty confident; It has made me confident; I feel a little bit more confident"). Others referred to how instructional coaching influenced their confidence to engage with colleagues about their professional learning. For example, Participants 1 and 5 explain how instructional coaching allowed their confidence not to be changed but to be "reinforced," or perhaps reactivated, with new and existing relationships with teachers:

Participant 1: ... I guess it's just helped me maintain my confidence with my ability to help my colleagues, elementary and secondary and meet them where they are at or where they need to be. I have access to resources and contacts and people to connect them with and I think it has been beneficial for me to have this opportunity to sort of reinforce what I have been doing and continue to support my colleagues.

Participant 5: I had a high level of confidence at the outset because I have done this type of work before, but this reinforced that in an elementary setting. I had done work in an elementary setting but I think my confidence in working with a variety of grade levels from junior to intermediate [grades 5-10] was certainly increased and seeing the variety of challenges and barriers that exist for teachers in that setting I think helped me to structure the coaching opportunity in a way that was more useful for the participants.

Others spoke of how they supported educators in their professional learning, feeling more confidence in how they "frame questions" or collaborated, finding "solutions together." Participant 11 provided a helpful account, explaining how learning about instructional coaching gave her more confidence to enact her role as a curriculum consultant more effectively than she had been able to do previously:

It has made me confident because as a consultant you feel like you should have all the answers. And in your workshops, you should present this wonderful content and everyone should leave saying "That was amazing" and "I learned so much stuff and so much new information". And to me, with this [instructional coaching] model, it does not have to come from me.... It's let's work on this together and find solutions together.

While qualitative data supported statistical increases in confidence as reflected by the survey results through the duration of the project, few participants felt those changes were dramatic. This may be due to the limited amount of time over which the project was implemented or that many were learning about instructional coaching for the first time.

\section{Importance-Utility Value}

As explained earlier, analysis of quantitative data showed statistically significant increases from initial- to posttest $(p=.004)$, with analysis of qualitative data offering insights into reasons for this increase. Key features of participants' views of the value of instructional coaching included it being learner-centered and job-embedded, as well as the iterative processes involved.

The emphasis on the needs of teachers-as-learners was a feature that stood out for many instructional coaches. Specifically, the focus of professional learning in instructional coaching is based on teachers' specific needs based in the particular contexts of their work. Participant 4 spoke of instructional coaching in relation to contemporary perspectives of professional learning expressed by Parker and Patton (2016) and Parker et al. (2016), where the teacher's specific needs are put before needs identified by external authorities, stating:

Having a teacher voice is critical so they get input into their own learning and that is where you get the buy-in and you can move forward with them because that's where they see the benefits. They see it job-embedded within their own classroom.

Participant 13 presented a similar view of the value of instructional coaching in the midtest focus group but recognized a tension inherent in contemporary approaches to professional learning, that being the trade-off between deep and rich learning to a small group of teachers compared with surface-level learning to a large group. She reconciled this tension later in the same focus group interview, explaining:

... You think of those big sessions that you do with 50-60 people: you don't get that relationship; you don't get that deep learning. Whereas, if it's a small group of two or three ... 20 even is small compared to the big sessions that we have done! [Instructional coaching] allows you much more focus so your intentions are going deeper and it is reflective of the needs [of the educators]. If you pull 50-60 people together you have 5060 different needs, whereas if you pull two, three, seven, or twenty you have got four, five, or six where you can focus on so much more .... We might not need more money, but it is how we are spending our money, it's the focus and intention of where that money is going. We don't need to pull 50-60 people out for a full day anymore. 
Time and money were recurring issues that arose as barriers to effective professional learning; however, we might interpret from Participant 13's comment that it is not the dollar amount that should be the main concern but how the money is spent in various forms of professional learning. She believed that the depth of learning for a smaller number of teachers offered by instructional coaching should be a more highly valued outcome by those who make decisions about how professional learning resources are allocated and spent.

The individualized, ongoing nature of interaction during the instructional coaching intervention was also viewed as a valuable feature. The sustained opportunities for engagement with teachers were viewed as particularly valuable, especially when compared with more traditional forms of professional learning. For Participant 12 , the value attached to instructional coaching was tracked from the mid to post focus groups. She said:

Mid-test: [Instructional coaching] is ensuring a certain follow through as opposed to ... just kind of feed [them] and they leave, so you never know: Did they actually swallow that pill? Did they digest it? What did they do with it? So I think that's the part I am most excited about because I have done some accompaniment with some teachers in my Board that I have met with once or twice and we exchanged emails, but I never actually know if it worked out okay in the end. So I think that I am excited about this one because I will be able to see ... some fruits of the labor.

Post-test: [Instructional coaching] is not something that we have practiced in our Board and I think that it makes a difference in the contact, the individual contact that I have with each teacher ... it is something that I see the benefits of and I think we will adopt more, or I will adopt more in my training with teachers.

From the comments offered by Participant 12, we can see she was hopeful about the opportunity to more consistently follow-up with particular teachers about the ways they have been able to implement their learning. Comments such as this capture an important element of the perceived value of instructional coaching, that it was important and useful not only for the ways it helped foster improved instruction for teachers but also for its potential to improve the type and quality of collegial relationships among teachers invested in and committed to their own professional learning and those with whom they work on a day-to-day basis.

For example, Participant 8 noted how instructional coaching led to some teachers being more open to working with consultants, creating opportunities for collaborative learning:

I ... would say that the added bonus was a deeper understanding of what it is to be a colleague and a coach and it hasn't been smooth all the time, but they too are learning about the relationships between colleagues and how you get people to open up their doors and that's also, I think, been a valuable experience.

An important point raised in the second focus group interview was the value that instructional coaches placed on learning about instructional coaching with and from other instructional coaches. In the October 2016 orientation provided by Ophea (mid), coaches learned about the theories behind instructional coaching in greater depth and generated some useful techniques for posing questions to teachers with whom they were working. However, in the focus group that followed the orientation session, one participant suggested the time would have been better spent engaging with others learning to become instructional coaches, providing opportunities for collective problem-solving or hearing some examples of successes or failures from the coaches:

In the future, I think it would be important to set a time for participants to work together since we don't have much time to do so otherwise, and then set a time for participants to get engaged in a learning process for themselves.

This insight led Ophea to change how they approached several learning tasks for the coaches in the latter part of the intervention, encouraging them to learn about the nature of instructional coaching (by providing them with electronic articles and so on) in their own time, while using as much face-to-face time as they could to collaborate and work together.

Despite the promise seen in instructional coaching, Participant 2 suggested that, even with its observed benefits, it would take time for teachers to come to terms with this approach and other individualized forms of professional learning. He suggested that some teachers perceived that a colleague or leader coming to observe them in their classroom meant that they were not doing their job well. It was going to take concerted efforts on the parts of coaches, administrators, and colleagues to have some teachers see instructional coaching as an opportunity for professional growth rather than as a corrective measure:

I think the coaching model is still fairly new and I think many people are still fairly afraid of it. But as this becomes a regular practice of each school board, people will see it as more of an opportunity and less as: "Oh, someone is coming to help me because I am no good". I think this is a practice that should continue. The time issue; the time to reflect is a practice that we need to develop.

\section{A Summary of Overall Experiences Learning About Instructional Coaching}

In the posttest survey, participants were asked two questions: (a) If the instructional coaching initiative were offered again, would you be willing and able to continue being involved? and (b) If this opportunity were offered again, would you recommend it to a colleague? Of the 14 responses from participants, $13(92.86 \%)$ said "Yes" and $1(7.14 \%)$ said "No" to the first question, with results being the same for the second question. Focus group data included several reasons why:

Participant 8: I would do it again in a heartbeat. It has given me a great area of focus [... ]. I got to see something in place that I think is really valuable and I am grateful for it ... I am not sure I would have been invited in anywhere and [...] it opened doors for me.

Others also suggested instructional coaching provided them with a helpful approach to professional learning that allowed them to enter teachers' classrooms and context in a nonthreatening way, and also in a way that was focused on the teacher's personal learning needs rather than on the needs or agendas of a school board or arm of government.

Many participants indicated they would also participate in the initiative again; however, they felt that some structures should be altered to provide more opportunities for collaboration among coaches. Furthermore, people who were going to become inducted into the role of instructional coach should be aware of the 
significant commitment of time and energy on top of one's already busy workload. It was acknowledged that learning to become an instructional coach took time, as did the process of instructional coaching itself. With these reservations in mind, we are still able to infer that participants had a positive experience learning to become instructional coaches and found it was a valuable experience for their learning and their professional role.

\section{Discussion}

This study demonstrates the mostly positive experiences of a cohort of H\&PE teachers and consultants who were learning to become instructional coaches. As a contemporary form of professional learning, instructional coaching exemplifies many features of signature pedagogies of professional learning in physical education (Parker et al., 2016), in that it is collaborative and involves a community of teachers-as-learners, is job-embedded, provides participants with some ownership and investment in the process, and enhances the knowledge and skills of those participants in the professional learning process (Desimone \& Pak, 2017; Knight, 2009). Guided by the tenets of expectancy-value theory, analysis of quantitative data revealed positive and statistically significant ( $p$ $<.05$ ) relationships between understanding and self-efficacy at each of three assessment points, while the relationships between IUV, understanding, and self-efficacy increased significantly between the initial- and posttest. We cannot make claims from the data that the change in understanding of the H\&PE curriculum came specifically as a result of participants' engagement with instructional coaching and some caution is needed in interpreting these statistical differences due to the small sample size.

Despite such limitations in the quantitative analysis, qualitative data analysis helps to bolster several claims, generally supporting the statistical findings while enabling a deeper understanding of reasons for the reported changes. The collaborative nature of instructional coaching was reported to be of particular importance to the learning experiences of participants, contributing to changes in their understanding, self-efficacy, and value placed on both instructional coaching and the revised H\&PE curriculum. Moreover, participants acknowledged the job-embedded nature of instructional coaching, which enabled coaches to work with teachers on issues teachers themselves wanted support with rather than on issues dictated by an external body, such as a school board or government ministry. This finding builds on and lends support to claims made by Patton et al. (2012) and Patton and Parker (2014) about the conceptualizations of teacher learning that tend to be held by professional learning facilitators in physical education, holding constructivist beliefs that emphasize the social nature of learning and privileging of the needs of teachers in their own contexts.

One recommendation for future work is to consider a larger pool of teachers/consultants who are learning to become instructional coaches, so that both broader and deeper perspectives of their experiences in learning to become instructional coaches are gained. As we acknowledged earlier, it is also important to consider the experiences of teachers who are engaged in the instructional coaching process - those whose classrooms are providing the context for professional learning. We are currently engaged in this work but also encourage others to do likewise in their particular contexts. In future studies, it would be useful to analyze several demographic variables of teachers relative to their engagement. For instance, Foley (2011) found that, in addition to value and expectancy, teachers' education, grade level, and years in a particular grade level predicted implementation of a teacher intervention, and it is worth considering the ways these factors may influence engagement with instructional coaching. As Patton et al. (2012) suggested, the selection of facilitators is an important consideration and understanding ways in which a host of variables and experiences inform facilitators' beliefs and subsequent engagement with a professional learning intervention is worth exploring.

As organizations such as Ophea who are responsible for the professional learning of teachers in H\&PE attempt to move toward forms of professional learning that are ongoing, collaborative, jobembedded, and based on the context-specific needs of teachers, we conclude by asserting that instructional coaching is one useful option, with the findings of this study offered as preliminary support for this claim. The strength of instructional coaching is evident in studies of mathematics (Bruce \& Ross, 2008) and literacy teachers (Lynch \& Ferguson, 2010), and we believe this research complements those findings, while grounding them specifically in the context of H\&PE. While we recognize that our findings represent the experiences of a small cohort of teachers in one context at a time of curriculum reform, we hope that others are in turn motivated to consider instructional coaching for the professional learning needs of teachers in other contexts.

\section{Acknowledgments}

In accordance with Human Kinetics policy and our ethical obligation as researchers, the first two authors were contracted by Ophea to evaluate instructional coaching with health and physical education teachers, the results of which are reported in this study.

\section{References}

Armour, K., Quennerstedt, M., Chambers, F., \& Makopoulou, K. (2017). What is 'effective' CPD for contemporary physical education teachers? A Deweyan framework. Sport, Education and Society, 22, 799-811. doi:10.1080/13573322.2015.1083000

Armour, K.M., \& Yelling, M.R. (2004). Continuing professional development for experienced physical education teachers: Towards effective provision. Sport, Education and Society, 9, 95-114. doi:10.1080/ 1357332042000175836

Baird, T.J., \& Clark, L.E. (2018). The 'look-ahead' professional development model: A professional development model for implementing new curriculum with a focus on instructional strategies. Professional Development in Education, 44, 326-341. doi:10.1080/19415257. 2017.1308424

Bruce, C.D., \& Ross, J.A. (2008). A model for increasing reform implementation and teacher efficacy: Teacher peer coaching in grades 3 and 6 mathematics. Canadian Journal of Education, 31, 346-370. doi:10. 2307/20466705

Darling-Hammond, L., Hyler, M.E., \& Gardner, M. (2017). Effective teacher professional development. Palo Alto, CA: Learning Policy Institute.

Darling-Hammond, L., \& McLaughlin, M.W. (2011). Policies that support professional development in an era of reform. Phi Delta Kappan, 92(6), 81-92. doi:10.1177/003172171109200622

Desimone, L.M., \& Pak, K. (2017). Instructional coaching as high-quality professional development. Theory Into Practice, 56, 3-12. doi:10. 1080/00405841.2016.1241947

Foley, L.S. (2011). Exploring K-3 teachers' implementation of comprehension strategy instruction (CSI) using expectancy-value theory. Literacy Research and Instruction, 50, 195-215. doi:10.1080/ 19388071.2010.505680 
Gallucci, C., Van Lare, M.D., Yoon, I.H., \& Boatright, B. (2010). Instructional coaching: Building theory about the role and organizational support for professional learning. American Educational Research Journal, 47, 919-963. doi:10.3102/0002831210371497

Goodyear, V.A., \& Casey, A. (2015). Innovation with change: Developing a community of practice to help teachers move beyond the 'honeymoon' of pedagogical renovation. Physical Education and Sport Pedagogy, 20, 186-203. doi:10.1080/17408989.2013.817012

Grove, C., Dixon, P.J., \& Pop, M.M. (2009). Research experiences for teachers: Influences related to expectancy and value of changes to practice in the American Classroom. Professional Development in Education, 35, 247-260. doi:10.1080/13674580802532712

Knight, J. (2009). Instructional coaching. In J. Knight (Ed.), Coaching: Approaches and perspectives (pp. 29-55). Thousand Oaks, CA: Corwin Press.

Loewenthal, K.M. (1996). An introduction to psychological tests and scales. London, UK: UCL Press Limited.

Lynch, J., \& Ferguson, K. (2010). Reflections of elementary school literacy coaches on practice: Roles and perspectives. Canadian Journal of Education, 33, 199-227.

Mangin, M.M., \& Dunsmore, K. (2015). How the framing of instructional coaching as a lever for systemic or individual reform influences the enactment of coaching. Educational Administration Quarterly, 51, 179-213. doi:10.1177/0013161X14522814

Ontario Ministry of Education. (2015a). The Ontario curriculum: Elementary. Health and Physical Education. Retrieved from http://www.edu. gov.on.ca/eng/curriculum/elementary/health.html\#display

Ontario Ministry of Education. (2015b). The Ontario curriculum: Secondary. Health and Physical Education. Retrieved from http://www. edu.gov.on.ca/eng/curriculum/secondary/health.html

Parker, M., \& Patton, K. (2016). What research tells us about effective continuing professional development for physical education teachers.
In C.D. Ennis (Ed.), Routledge handbook of physical education pedagogies (pp. 447-460). Abingdon, UK: Routledge.

Parker, M., Patton, K., \& O'Sullivan, M. (2016). Signature pedagogies in support of teachers' professional learning. Irish Educational Studies, 35, 137-153. doi:10.1080/03323315.2016.1141700

Patton, K., \& Parker, M. (2014). Moving from 'things to do on Monday' to student learning: Physical education professional development facilitators' views of success. Physical Education and Sport Pedagogy, 19, 60-75. doi:10.1080/17408989.2012.726980

Patton, K., Parker, M., \& Neutzling, M.M. (2012). Tennis shoes required: The role of the facilitator in professional development. Research Quarterly for Exercise and Sport, 83, 522-532. PubMed ID: 23367814 doi:10.1080/02701367.2012.10599141

Pintrich, P.R., Smith, D.A., Garcia, T., \& McKeachie, W.J. (1991). A manual for the use of the motivated strategies for learning questionnaire (MSLQ; Technical Report No. 91-B-004). Ann Arbor, MI: University of Michigan, School of Education.

Sparks, D. (2002). Designing powerful professional development for teachers and principals. Oxford, OH: National Staff Development Council.

Tabachnick, B.G., \& Fidell, L.S. (2006). Using multivariate statistics (5th ed.). New York, NY: Harper Collins.

Thomson, M.M., \& Kaufmann, E. (2013). Elementary teachers' views of their science professional development attendance: An expectancyvalue approach. Eurasia Journal of Mathematics, Science and Technology Education, 9, 45-58. doi:10.12973/eurasia.2013.915a

Wigfield, A., \& Eccles, J.S. (2000). Expectancy-value theory of achievement motivation. Contemporary Educational Psychology, 25, 68-81. doi:10.1006/ceps.1999.1015

Woulfin, S.L., \& Rigby, J.G. (2017). Coaching for coherence: How instructional coaches lead change in the evaluation era. Educational Researcher, 46, 323-328. doi:10.3102/0013189X17725525 